\title{
Effect of Structural and Psychological Empowerment on Newly Graduated Nurses' Organizational Commitment at Hospitals in Assiut City
}

\author{
Eman Kamel Hossny, Mohammad Hassan Qayed \& Hala Ramzy Youssef. \\ Assistant lecturer in nursing administration department, faculty of nursing, Assiut University Egypt. \\ Professor of Public Health \& Community Medicine, Faculty of Medicine, Assiut University Egypt. \\ Assistant professor of nursing administration, faculty of nursing, Assiut University Egypt.
}

\begin{abstract}
The aim of this study to assessing the effect of structural and Psychological empowerment on newly graduated nurses' organizational commitment. Setting the study was conducted at Assiut University Hospitals, Health Insurance Hospital and two hospitals affiliated to Ministry of Health namely: Assiut General Hospital (El-Shamla Hospital) and El-Eman General Hospital in Assiut city Design descriptive correlational design was used. Subject It included all staff nurses who had at most two years' experience (136). Tools data collection tools were socio demographic data sheet, structural empowerment (conditions of work effectiveness questionnaire), psychological empowerment questionnaire, and organizational commitment scale. Results more than half of new graduated nurses reported high structural empowerment in ministry of health hospital compared with other two hospitals. Majority of nurses in different hospitals are psychologically empowered. Conclusion There was a weak negative relationship between structural empowerment and organizational commitment. Also, there was a moderate negative relationship between psychological empowerment and organizational commitment. Recommendation Carry out job orientation program for newly graduated nurses at the beginning of employment with the profession of employee policy handbook.
\end{abstract}

Keywords : Structural Empowerment, Psychological Empowerment, Organizational Commitment \& New Graduated Nurses.

\section{Introduction}

New graduates face many challenges as they begin their nursing careers. Transitioning from student status to the full professional role requires gaining clinical expertise and self-efficacy for practice within a work environment that supports both professional nursing practice and more positive outcomes for patients (Beecroft et al., 2008).

New nursing graduates must be supported in their workplace. It is imperative that leaders in health care organizations where nurses practice build the foundational supports to assist graduate nurses in their ability to access workplace empowerment structures. These factors are reinforce the need to create working environments that support nursing graduates; building a healthy stable workforce for the future of health care and the nursing profession (Bushell, 2013).

According to (Borghei et al., 2010) there are two concepts of empowerment stated in the management and organizational literature. First, according to Kanter's theory of structural empowerment, employees are empowered when they are given access to empowerment structures to accomplish their work Kanter (1977, 1993) cited by Bushell, (2013) stated that promotion of an empowering workplace is largely dependent on the presence of two important social structures: opportunity and power. The structure of opportunity provides employees with the prospect of advancing within an organization, as well as the chance to develop their knowledge and skills. Employees with low access to opportunity have been found to exhibit stuck behavior, resulting in decreased organizational commitment. The structure of power results from having access to three important sources: Information, support and resources (Kanter, 1979).

Access to information consists of the data, knowledge and expertise required to carry out one's job responsibilities. Access to support refers to the receipt of feedback and guidance from supervisors, peers and subordinates. Finally, access to resources refers to employees' capacity to obtain the money, time and materials needed to accomplish their work (Kanter, 1979).

Kanter's (1977, 1993) cited by Bushell (2013) theory is the lines of power that evolve from formal and informal systems. Formal power is high when jobs are central to the achievement of organizational goals and permit flexibility in how work is accomplished. Informal power is high when strong relationships among peers, superiors, subordinates and political contacts are encouraged. High levels of formal and informal power facilitate access to the structures of power and opportunity that enable 
employees to accomplish their Work in meaningful ways (Laschinger \& Finegan, 2005a). Second, a psychological perspective is another form of empowerment. In this approach, empowerment is described as the manifestation of four cognitions regarding a worker's orientation to their role: meaning, competence, self-determination, and impact or outcome.

Empowered employees becoming more committed to the organization, and overall organizational effectiveness will improve. Employees' access to information which can be the first step to empowerment. Employees must have open communications with management, and have information regarding the function and structure of the organization. Lack of information can create powerlessness (Carter \& Ryan, 2011).

Fred (2008) definer organizational commitment as "an attitude reflecting employees' loyalty to their organization and is an ongoing process through which organizational participants express their concern for the organization and its continued success and well-being". Employee commitment is highly important as the success of the organization is highly related to the commitment of employees. Highly committed employee will have a clear vision and mission of the organization, which strongly bounds him with his duties and he will show the resident behavior. (Ambreen, 2011).

Meyer \& Allen, (1997) divided organizational commitment into three sub-dimensions, namely: 1) affective commitment, 2) continuance commitment and 3 ) normative commitment

\section{Significance of the study}

The early years of practice represents a significant confidence building phase for newly graduated nurses. Yet many new members are exposed to disempowering experiences along with many nurses approaching retirement and the nursing shortage is projected to increase. Understanding the factors that influence new graduates' sense of organizational commitment is therefore critical to prevent further attrition of new members (Longo, 2007).

\section{Research question}

To what extent the empowerment can affect the employee' organizational commitment? This study will be carried out to answer this question.

\section{Aim of the study}

To assessing the effect of structural and Psychological empowerment on newly graduated nurses' organizational commitment.

\section{Subjects and methods}

The methodology pursued in the conduction of the study will be described under four designs, namely technical, administrative, operational, and statistical design.

Technical design

This design involves the research design, the setting, subject, and tools of data collection.

\section{Research design}

The study was developed with a descriptive correlational study design.

Setting

The present study had been conducted at seven hospitals affiliated to three main health care sectors: namely; (1) four hospitals affiliated to Assiut university hospitals namely: main Assiut University Hospital; Pediatric Health Hospital; Woman Health Hospital; South Egypt Cancer Institute, (2) Assiut Health Insurance Hospital (El-Mabarra Hospital) and (3) two hospitals affiliated to Ministry of Health included Assiut General Hospital (El-Shamlla) and El- Eman General Hospital, at Assiut City.

Subjects

The present study targeted all newly graduated nurses who work at the predetermined study settings and who welcomed to participate in the study. The total number of staff nurses who had participated in the study composed (136).

Tools of data collection

Data for the present study were collected using the following four tools:

1) Socio demographic data sheet

It was designed to collect the socio demographic data about the study participants as age, gender, marital status, educational level, years of experience, and place of work.

2) Structural empowerment (Conditions of Work Effectiveness Questionnaire) (CWEQ-II)

It was developed by Laschinger et al., (2001), \& translated by the researcher, the questionnaire consists of 19 items it used to measure structure empowerment according to kanter's, divided under six main dimensions they namely: 1) Access to opportunity (3 items); 2) Access to information (3 items); 3) Access to support (3 items); 4) Access to resources (3 items); 5) Formal power (3 items); and 6) Informal power (4 items); each subscale includes three items, except informal power which includes four items. Subjects responses were measured on a three- point Likert Scale from a lot (3), sometimes (2), and non (1).

3) Psychological empowerment questionnaire It had been developed by Spreitzer (1995), \& translated by the researcher, it used to measure nurses' psychological empowerment. The 
questionnaire includes 12 items divided into four subscale, namely: 1) meaning (three items), 2) competence (three items), 3) self- actualization (three items), and 4) affecting (three items). It was measured on a three point Likert Scale agree (3), neutral (2) and disagree (1).

\section{4) Organizational commitment scale (OCS)}

It was developed by Meyer et al., (1993), and translated by the researcher. It was used to measure nurses' organizational commitment. It consists of 18 items divided under three subscales, namely: 1) affective occupational commitment (six items), 2) continuous occupational commitment (six items), and 3) normative occupational commitment (six items). It is measured on a three point likert scale agree (3), neutral (2) and disagree (1).

\section{Scoring system}

Regarding psychological empowerment, and organizational commitment scales, the responses with a three point likert scale from 1 to 3 when the participants' responses were "agree" scored (3), "neutral" scored (2), and "disagree" scored (1). While regarding the structural empowerment the responses were "a lot" scored (3), "sometime" scored (2), and "non" scored (1). The scores of the items were summed-up and divided by the number of the items, giving the mean score. These scores were converted into a mean percent score. Then the means and standard deviations of the scores were computed. If the mean scores of a participant were $\geq 60 \%$ this means high but if $\leq 60 \%$ this means low.

\section{Administrative design}

Obtaining the approval from the concerned bodies to carry out the present study at the hospitals they headed.

\section{Ethical considerations}

- The study proposal took agreement from the ethical committee in the faculty of nursing, Assiut University.

- New graduated nurses have ethical rights to participate or refuse participation in the present study.

- An informed consent were obtained from the study participants orally before being involved in the study after explanation of the nature and purpose of the study and there are no risks or cost in participation, confidentiality of information for each subject who agree to participate and to fill the questionnaire.

\section{Operational design}

\section{1) Preparatory phase}

This phase consumed about ten months from "May 2011 to February 2012", and includes the following events: Reviewing the relevant literatures concerning the study topics, and translation of the study tools into Arabic language.

\section{Pilot study}

A Pilot study had been conducted to test the study tools clarity, reliability, feasibility, and understandability reliability was tested through measuring internal consistency of the tools using Cronbach's alpha coefficients method. The pilot study included $10.0 \%$ of the total sample size (i.e.16 newly graduate nurses. The pilot study data were analyzed, and necessary modifications were done prior to finalization of the study tools. Clarity has also served in estimating the time needed for filling the forms, and it revealed that the questionnaire would take about half an hour for filling. A brief explanation of the purpose of the study was provided to every participant in the pilot study and then he/she was provided with a copy of the study tools. Data were collected by the investigator from the defined study sample using the questionnaire. New graduated nurses included in the pilot study were not excluded from study sample.

\section{Field work}

The researcher met with the study subjects individually to explain the purpose of the study; then seek their participation. After obtaining approval to participate in the study, the study tool handled to all of them to be filled. All of them welcomed to participate in the study. Each interview took about half an hour. The whole duration for data collection took about five months from September 2013 to January 2014.

\section{Statistical design}

Data entry and analysis were done using SPSS version 12 (Statistical Package for Social Science). Data were presented using descriptive statistics in the form of frequencies and percentages, mean, and standard deviations. For multiple group comparisons of quantitative data, one-way analysis of variance test (ANOVA) was used. Pearson correlation analysis was used for assessment of the inter-relationships among quantitative variables. Multiple regressions were used to test the study hypothesis. Statistical significance was considered at $\mathrm{p}<0.05$. 


\section{Results}

Table (1): Socio demographic data of the study nurses at different health care sectors in Assiut City (n=136).

\begin{tabular}{|c|c|c|c|c|c|c|}
\hline \multirow[t]{2}{*}{$\begin{array}{c}\text { Demographic } \\
\text { Characteristics of the study } \\
\text { nurses }\end{array}$} & \multicolumn{2}{|c|}{$\begin{array}{c}\text { Assiut University } \\
\text { Hospitals } \\
(\mathbf{N}=\mathbf{5 5})\end{array}$} & \multicolumn{2}{|c|}{$\begin{array}{c}\text { Health Insurance } \\
\text { Hospital } \\
(\mathbf{N}=\mathbf{1 8})\end{array}$} & \multicolumn{2}{|c|}{$\begin{array}{c}\text { Ministry of Health } \\
\text { Hospitals } \\
(\mathbf{N}=\mathbf{6 3})\end{array}$} \\
\hline & No. & $\%$ & No. & $\%$ & No. & $\%$ \\
\hline \multicolumn{7}{|l|}{ Age:(years) } \\
\hline$<20$ & 3 & 5.4 & 1 & 5.6 & 1 & 1.6 \\
\hline $20-$ & 51 & 91.1 & 17 & 94.4 & 59 & 95.2 \\
\hline $25^{+}$ & 2 & 3.5 & 0 & 0.0 & 2 & 3.2 \\
\hline Mean \pm SD & \multicolumn{2}{|c|}{ 1 } & \multicolumn{2}{|c|}{$\frac{1}{21.33 \pm 0.97}$} & \multicolumn{2}{|c|}{ 21.52+1.25 } \\
\hline \multicolumn{7}{|l|}{ Gender } \\
\hline Female & 53 & 94.6 & 17 & 94.4 & 56 & 90.3 \\
\hline Male & 3 & 5.4 & 1 & 5.6 & 6 & 9.7 \\
\hline \multicolumn{7}{|l|}{ Marital status } \\
\hline Single & 35 & 62.5 & 17 & 94.4 & 43 & 69.4 \\
\hline Married & 21 & 37.5 & 1 & 5.6 & 19 & 30.6 \\
\hline \multicolumn{7}{|l|}{ Qualification } \\
\hline Technical Institute of Nursing & 48 & 85.8 & 17 & 94.5 & 59 & 95.2 \\
\hline Secondary Nursing School & 8 & 14.2 & 1 & 5.5 & 3 & 4.8 \\
\hline
\end{tabular}

Table (2): Structural empowerment as reported by newly graduated nurses at different health care sectors in Assiut City, $(\mathbf{n = 1 3 6})$.

\begin{tabular}{|c|c|c|c|c|c|}
\hline \multirow{3}{*}{ Study settings } & \multicolumn{4}{|c|}{ Structural Empowerment } & \multirow{3}{*}{ P. Value } \\
\hline & \multicolumn{2}{|c|}{ High } & \multicolumn{2}{|c|}{ Low } & \\
\hline & No. & $\%$ & No. & $\%$ & \\
\hline Assuit University hospital $(\mathrm{n}=55)$ & 22 & 39.0 & 34 & 61.0 & \multirow{3}{*}{0.090} \\
\hline Health Insurance hospital $(n=18)$ & 7 & 39.0 & 11 & 61.0 & \\
\hline Ministry of Health hospitals $(n=63)$ & 36 & 58.0 & 26 & 42.0 & \\
\hline
\end{tabular}

ANOVA test

Statistical significant difference $(P<0.05)$

Table (3): Psychological empowerment as reported by newly graduated nurses at different health care sectors in Assiut City, $(\mathbf{n}=136)$.

\begin{tabular}{|c|c|c|c|c|c|}
\hline \multirow{3}{*}{ Study settings } & \multicolumn{4}{|c|}{ Psychological empowerment } & \multirow{3}{*}{$\begin{array}{c}P . \\
\text { Value }\end{array}$} \\
\hline & \multicolumn{2}{|c|}{ High } & \multicolumn{2}{|c|}{ Low } & \\
\hline & No. & $\%$ & No. & $\%$ & \\
\hline Assiut University hospital (n=55) & 46 & 82.0 & 10 & $\overline{18.0}$ & \multirow{3}{*}{0.550} \\
\hline Health Insurance hospital $(\mathrm{n}=18)$ & 16 & 89.0 & 2 & 11.0 & \\
\hline Ministry of Health hospitals $(n=63)$ & 55 & 89.0 & 7 & 11.0 & \\
\hline
\end{tabular}

Table (4): Organizational commitment as reported by new graduated nurses at different health care sectors in Assiut City, $(n=136)$

\begin{tabular}{|l|c|c|c|c|c|}
\hline \multirow{2}{*}{\multicolumn{1}{|c|}{ Study settings }} & \multicolumn{4}{c|}{ Organizational commitment } & \\
\cline { 2 - 5 } & \multicolumn{3}{|c|}{ High } & \multicolumn{3}{c|}{ Low } \\
\cline { 2 - 5 } & No. & $\mathbf{\%}$ & No. & \% & Value \\
\hline Assuit University hospital $(\mathrm{n}=55)$ & 30 & 54.0 & 26 & 46.0 & \\
\hline Health Insurance hospital $(\mathrm{n}=18)$ & 12 & 67.0 & 6 & 33.0 & \multirow{2}{*}{0.069} \\
\hline Ministry of Health hospitals $(\mathrm{n}=63)$ & 24 & 39.0 & 38 & 61.0 & \\
\hline
\end{tabular}


Table (5): Correlation matrix of the independent and dependent variables among the study nurses at different health care sectors in Assiut City, $(n=136)$.

\begin{tabular}{|l|c|c|c|}
\hline \multicolumn{1}{|c|}{ Variables } & $\begin{array}{c}\text { Structural } \\
\text { Empowerment }\end{array}$ & $\begin{array}{c}\text { Psychological } \\
\text { Empowerment }\end{array}$ & $\begin{array}{c}\text { Organizational } \\
\text { Commitment }\end{array}$ \\
\hline 1-Structural empowerment. & 0.298 & & \\
\hline 2-Psychological empowerment. & -0.090 & -0.448 & \\
\hline 3-Organizational commitment. & \multicolumn{3}{|l|}{} \\
\hline
\end{tabular}

Independent variables: (Workplace civility climate, Structural and Psychological empowerment

Dependent variables: (Organizational commitment)

Socio demographic characteristics of the study nurses in the study sample depicted at Table (1): As regarding to Assiut University Hospital, a high percent of them are females, graduated from the technical institute, and single $(94.6 \%, 85.8 \%$ and $62.5 \%)$ respectively. Their mean age was (1.13). As regarding to Health insurance Hospital, a high percent of them are females, graduated from the technical institute, and single $(94.4 \%, 94.5 \%$ and $94.4 \%$ ) respectively. Their mean age was (21.33). As regarding to Ministry of Health Hospital, a high percent of them are females, graduated from the technical institute, and single $(90.3 \%, 95.2 \%$ and $69.4 \%$ ) respectively. Their mean age was (21.52).

Table (2) : reveals that structural empowerment as reported by the study nurses at study sample. More than half of study nurses (58.0\%) perceived structural empowerment high in Ministry of health hospital compared to Health insurance hospital and Assuit University hospitals. There was no statistical significant difference among study nurses regarding structural empowerment in different hospitals $(\mathrm{P}<$ 0.05).

Psychological empowerment as reported by the study nurses at study sample described in Table (3): Majority of nurses in different hospitals were highly psychological empowered $(89.0 \%$, $89.0 \%$ \& $82.0 \%$ ) respectively. There was no statistical significant difference among study nurses regarding total psychological empowerment in different hospitals $(\mathrm{P}<0.05)$.

Table (4): reveals that organizational commitment as reported by the study nurses at study sample. High percent of study nurses have high organizational commitment to Health insurance hospital (67.0), And high percent of them have low organizational commitment in Ministry of health hospital (61.0\%).

Table (5): depicts that correlation matrix between independent and dependent variables among study nurses at study sample. There was weak negative correlation between structural empowerment and organizational commitment (-0.090). Also, there was moderate negative correlation between psychological empowerment and organizational commitment (-0.448).

\section{Discussion}

With more organizations looking for employees who take the initiative and respond creatively to the challenges of the job, empowerment becomes important at both individual and organizational levels. Empowered employees are generally more committed and effective at work (Ramos \& Alesy 2014).

A study finding of (table 2) demonstrates no statistical significant differences among study nurses regarding structural empowerment in three hospitals. The study findings showed low empowerment structure in Assiut University Hospitals and Health Insurance Hospital, this might be duo to new graduated nurses cannot access to the information, support and resources required to perform their work effectively. In addition, they do not have opportunities to advance within the organization or to learn and grow through challenging work experiences or learning opportunities. This result is congruent with Yakob (2002) cited in (El- Salam, 2008) who reported that staff nurses' total empowerment scores were relatively low, and by Safaan (2003) cited in (El-Salam et al., 2008) who stated that staff nurses had lower scores of work empowerment than nurse managers.

Above half of study nurses are perceived structural empowerment high in Ministry of Health Hospitals compared to Assiut University Hospitals and Health Insurance Hospital. With this respect, Cho et al., (2006) reported that new graduated nurses feel more engaged and committed to their work place when empowerment structures are in place. Influential partnerships with other staff are likely to increase the commitment of novice nurses who might otherwise feel like outsiders amongst more senior colleagues.

The findings of table (3) included in the present study reveals that the majority of study nurses have high psychological empowerment in three hospitals. This might be because when staff nurses become psychologically empowered; they can be adapted, able to cope with stressors, and more satisfied with the work. Their intent to stay in the organization increased and they become more loyal, more 
productive, and have the power to work in the organization. These findings contradicted with the findings of (Ahmed, 2005) who study the relationship between leadership style and psychological empowerment and its effect on job satisfaction of nurses in Assiut University Hospitals. It indicates that the level of psychological empowerment was mostly weak among study nurses.

As regards organizational commitment (table 4), the findings of the present study reveals that about two third of study nurses reported high commitment to Health Insurance Hospital, and half of them are committed to Assiut University Hospitals compared to Ministry of Health Hospital. This may be attributed to that receiving support leads to more willingness of nurses to extra- effort, praise their job, and feel proud of organization, so their intent to stay increase. Organizational commitment level shows how long employees tend to stay in organization.Lower commitment level among employee shows that they will leave the organization soon. The commitment level among employee can be seen as a predictor whether the employee will stay longer or leave the organization (Nabila \& Ambad, 2012)

The study finding (table5) reveals that a weak negative correlation between structural empowerment and organizational commitment. This might be related to the study nurses few months experience they have in workplace as appear in (table1) characterized by uncooperative relationships within a bureaucratic structure. Roche et al., (2004) found an orientation program resulted in higher retention rates for both newly graduated and newly-hired nurses. This finding support the importance of empowering work structures as a means of enhancing the retention and commitment of newly-graduated nurses.

Cho et al., (2006) found that structural empowerment had both a direct and an indirect effect on organizational commitment. Structural empowerment enables employees to accomplish their work and to achieve positive work behaviors and as a result, they experience greater job satisfaction, commitment, trust and low burnout.

Liu et al., (2007) found that increase in the perception of work empowerment; will lead to the increase in organizational commitment. When the employees are given more responsibilities, are assigned tasks that are important to the organization performance, and are allowed to have opportunities to make significant decisions, giving them more chances to voice out their personal opinions, they will in turn feel more empowered. Empowered employees tend to be more willing to remain with the organization and work harder.
From another prospective the findings of the present study revealed a moderate negative correlation between psychological empowerment and organizational commitment. In this respect, organizational commitment of nurses may be understood as a response to several environmental occurrence and personal characteristics (Acron et al., 1997). Nurses with high self-efficacy feel a greater sense of power, which in turn would be expected to yield greater commitment to the organization (Bowen \& Lawler, 2006).

This findings are supported by the findings of Laschinger et al., (2001a) who found that no published studies of newly-graduated nurses' experiences of psychological empowerment. The data from the current study supports Spreitzer's hypothesis that empowered workers exhibit higher levels of organizational commitment.

On the other hand, Jafari et al., (2013); Chang et al., (2010) \& Laschinger et al., (2009) found that the organizational commitment can be predicted by psychological empowerment. However, congruent with other studies of (Jha, 2009, Laschinger et al., 2009, \& Ambad et al., 2012) found that only two or three psychological empowerment dimensions predicting organizational commitment.

\section{Conclusions}

New graduated nurses reported low structural empowerment in Assiut University Hospitals and Health Insurance Hospital, while they reported high commitment in the same hospitals. New graduated nurses reported high psychological empowerment in all study hospitals.

\section{Recommendations}

In the light of the results of this study, the following recommendations are suggested: Carry out orientation program for newly graduated nurses at the beginning of employment with the profession of employee policy handbook to inform them about hospital policies.

Allow nurses to have opportunities to make significant decisions, and giving them more chances to voice their personal opinions to access formal power. All managers at all levels should recognize that the nurses should have power to work in the organization as they are sharing in the organization success. Further studies on large number of nurses with different categories are needed.

\section{References}

1. Acron S., Ranter P., \& Crawford M., (1997): Decentralization as a determinant of and 
organizational commitment among nurse managers. Nurs. Res, 46 (1).52-58.

2. Ahmed E., (2005): The relationship between leadership style and empowerment and its effect on job satisfaction of nurses in Assiut University hospitals, msc. Thesis Faculty of nursing, Assiut University. Egypt.

3. Ambad A., Nabila S., \& Bahron A., (2012): Psychological Empowerment: The influence on organizational commitment among employees in the construction sector. Journal of Global Business Management, 8(2) :73-81

4. Ambreen M., (2011): Impact of Implied Organizational Support on Organizational Commitment. European Journal of Business and Management, 3 (11): 41-45

5. Borghei R., Jandaghi G., Matin H., \& Dastani N., (2010): An examination of the relationship between empowerment and organizational commitment. International Journal of Human Sciences [Online]. 7:2. Available: http://www.insanbiliml eri.com/en

6. Beecroft P., Dorey F.and Wenten M., (2008): Turnover intention hl new graduate nurses: A multivariate analysis. The Journal of Advanced Nursing, 62(1), 41-52.

7. Bowen D., \& Lawler E., (2006): Empowering Service Employees. Sloan Management Review, (summer), 73-84.

8. Bushell P., (2013): New graduate nurses' structural empowerment and their experience of co-worker incivility and burnout . M.Sc. Thesis, The School of Graduate and Postdoctoral Studies, The University of Western Ontario, London, Ontario, Canada

9. Carter J., \& Ryan M., (2011) : The influence of empowerment and discourtesy on burnout and nurse retention research paper carter M.Sc. Thesis, Ball State University, Muncie, Indiana.

10. Chang L., Shih C., \& Lin S., (2010): The mediating role of psychological empowerment on job satisfaction and organizational commitment for school health nurses: A crosssectional questionnaire survey. International Journal of Nursing Studies. 47(4): 427-33.

11. Cho J., Laschinger H., \& Wong C., (2006): Workplace empowerment, work engagement and organizational commitment of new graduate nurses. Canadian Journal of Nursing Leadership 19,(3): 43-60.

12. El-Salam M., Ibrahim M., \& Hassanein S., (2008): Relationship between organizational climate and empowerment of nurses in Menoufiya hospitals, Egypt G.A. Eastern Mediterranean Health Journal, 14 (5)
13. Fred L., (2008): Organizational Behavior. 8th ed. Boston: Irwin McGraw-Hill.

14. Jafari V., Moradi M., \& Ahanchi M., (2013): An examination of the relationship between empowerment and organizational commitment (Case study Kurdistan province electric staff). Interdisciplinary Journal of Contemporary Research in Business; 4(12):860-868.

15. Jha S., (2009): Influence of psychological empowerment on affective, normative and continuance commitment: A study in Indian IT industry. International Journal of Organizational Behaviour;15(1): 53.

16. Kanter R., (1977): Men and women of the corporation. New York: Basic Books.

17. Kanter R., (1979): Power failure in management circuits. Harvard Business Review, July/August, 65-75.

18. Kanter R., (1993): Men and Women of the Corporation, $2^{\text {nd }}$ edn. Basic Books, New York, NY.

19. Laschinger H., (2001): Voices from the trenches: nurses' experiences of hospital restructuring in Ontario. Canadian journal of nursing leadership, 14(1):6-13.

20. Laschinger H., \& Finegan J., (2005): Using empowerment to build trust and respect in the workplace: A strategy for addressing the nursing shortage. Nursing Economics, 23, 6-13.

21. Laschinger S., Finegan J., \& Wilk P., (2009): New graduate burnout: The impact of professional practice environment, workplace civility, and empowerment. Nursing Economics, 27(6), 377-383.

22. Laschinger H., (2003): Voices from the trenches: nurses' experiences of hospital restructuring in Ontario. Canadian journal of nursing leadership, 14(1):6-13.

23. Liu A., Chiu W., \& Fellows R., (2007):.Enhancing commitment through work empowerment. Engineering, construction and architectural management, 14(6): 568-580.

24. Longo J., (2007): factored affecting registered nurses' job satisfaction and intend to leave. Doctor of nursing science dissertation. Florida Atlantic university. Florida.

25. Meyer J., \& Allen N., (1997) : Commitment in the Workplace: Theory, Research, and Application. Sage Publications.

26. Meyer J., Allen N., \& Smith C., (1993): Commitment to organizations and occupations: extension and test of a three-component conceptualizations. Journal of Applied Psychology.78: 538- 551.

27. Nabila S., \& Ambad A., (2012): Psychological Empowerment: The Influence on Organizational 
Commitment Among Employees in the Construction Sector The Journal of Global Business Management, 8(2): 171-176.

28. Ramos A., \& Alesy B., (2014): Empowering Employees: structural empowerment as antecedent of job satisfaction in university setting, research articles, 7(1), 34 .

29. Roche J., Lamoureux E., \& Teehan T., (2004): A partnership between nursing education and practice: Using an empowerment model to retain new nurse. Journal of Nursing Administration, 34(1), 26-32.

30. Safaan S., (2003): Study of the concept of empowermentamong staff nurses and nursemanagers at Menoufiya University hospital. M.Sc. Thesis, Faculty of Nursing, University of Menoufiya, Egypt

31. Spreitzer G., (1995): Psychological empowerment in the workplace: dimensions, measurement, and validation. Academy of Management Journal 38 (5): 1442-1465.

32. Yakob E., (2002): Work empowerment as perceived by nurses and physicians working at national heart institute. M.Sc. Thesis, Faculty of Nursing, Ain Shams University, Cairo, Egypt. 